\title{
Transarterial chemoembolization for early stage hepatocellular carcinoma decrease local tumor control and overall survival compared to radiofrequency ablation
}

\author{
Arnaud Hocquelet ${ }^{1,2}$, Olivier Seror ${ }^{3}$, Jean-Frédéric Blanc ${ }^{4}$, Nora Frulio ${ }^{1}$, Cécile \\ Salut $^{1}$, Jean-Charles Nault ${ }^{5}$ and Hervé Trillaud ${ }^{1,2}$ \\ ${ }^{1}$ Department of Diagnostic and Interventional Imaging, Hôpital Saint-André, Centre Hospitalier Universitaire de Bordeaux, \\ Bordeaux, France \\ ${ }^{2}$ EA IMOTION (Imagerie Moléculaire et Thérapies Innovantes en Oncologie) Université de Bordeaux, Bordeaux, France \\ ${ }^{3}$ Department of Radiology, Hôpital Jean Verdier (Assistance Publique-Hôpitaux de Paris), Bondy, France \\ ${ }^{4}$ Department of HepatoGastroenterology and Digestive oncology, Hôpital Saint-André, Centre Hospitalier Universitaire de \\ Bordeaux, Bordeaux, France \\ ${ }^{5}$ Inserm, Génomique Fonctionelle des Tumeurs Solides, Paris, France \\ Correspondence to: Arnaud Hocquelet, email: arnaud.hocquelet@gmail.com \\ Keywords: chemoembolization, therapeutic, radiofrequency ablation, carcinoma, hepatocellular \\ Received: June 07, $2016 \quad$ Accepted: October 21, $2016 \quad$ Published: October 26, 2016
}

Copyright: Hocquelet et al. This is an open-access article distributed under the terms of the Creative Commons Attribution License (CC-BY), which permits unrestricted use, distribution, and reproduction in any medium, provided the original author and source are credited.

\section{ABSTRACT}

Background \& Aims: To compare treatment failure and survival associated with ultrasound-guided radiofrequency ablation (RFA) and trans-arterial chemoembolization (TACE) for early-stage HCC in Child-Pugh A cirrhosis patients.

Methods: 122 cirrhotic patients (RFA: 61; TACE: 61) were well matched according to cirrhosis severity; tumor size and serum alpha-fetoprotein. TACE was performed in case of inconspicuous nodule on US or nodule with "at risk location". Treatment failure was defined as local tumor progression (LTP) and primary treatment failure (failing to obtain complete response after two treatment session). Treatment failure and overall survival (OS) were compared after coarsened exact matching. Cox proportional model to assess independent predictive factors was performed.

Results: No significant difference was seen for baseline characteristics between the two groups. Mean tumor size was $3 \mathrm{~cm}$ in both group with $41 \% \mathrm{HCC}>3 \mathrm{~cm}$. Treatment failure rates after TACE was $42.6 \%$ (14 primary treatment failures and 12 LTP) and $9.8 \%$ after RFA (no primary treatment failure and 6 LTP) $P<0.001$. TACE was the only predictive factor of treatment failure (Hazard ratio: 5.573). The 4-years OS after RFA and TACE were $54.1 \%$ and $31.5 \%(P=0.042)$, respectively.

Conclusion: For Child-Pugh A patients with early-stage HCC, alternative treatment as supra-selective TACE to RFA regarded as too challenging using common US guidance decrease significantly the local tumor control and overall survival. Efforts to improve feasibility of RFA especially for inconspicuous target have to be made.

\section{INTRODUCTION}

Hepatocellular carcinoma (HCC) is the fifth most common cancer and the second cause of cancer-related deaths [1]. As recommended by EASL clinical practice guidelines [1] single hepatocellular carcinoma and up to three hepatocellular carcinoma $<3 \mathrm{~cm}$ should be treated by transplantation, surgery resection (SR) or radiofrequency ablation (RFA). Due to the lack of transplants from cadaveric donors RFA is the first-line treatment for unresectable Child Pugh A HCC patients. Although TACE is recommended only for BCLC B HCC [1], this treatment is the most performed worldwide and it is frequently used for early-stage HCC. Indeed, thirty per cent of RFA can't be performed under ultrasound guidance because of tumor 
invisibility [2] and 15\% of RFA are not performed due to the "high-risk" location of the tumor [3]. Recent progress in imaging guidance as imaging fusion $[4,5]$ or cone-beam CT $[6,7]$ and using artificial pleural effusion or ascitis $[3,8]$, [9] have drastically reduced the RFA infeasibility rate. However these devices are mainly available on specialized tertiary centers, When not available, supraselective transarterial chemoembolization (segmental or subsegmental tumor feeding embolization) (TACE) [10] is frequently used as first-line treatment [11]. Furthermore several studies concluded that supra-selective TACE allows achievement of long-term survival rates comparable to RFA for early-HCC [12-14]. These studies explained the similar outcome by a less satisfactory effect of RFA on medium tumors (3-5 cm in diameter) and the ability of TACE treating satellite nodules. Indeed monopolar radiofrequency device offered a weak local disease control and complete necrosis for HCC larger than $3 \mathrm{~cm}[15,16]$. RFA technologies have been improved. No touch multibipolar RFA offered a larger complete necrosis rate than monopolar devices for medium HCC [16-19] and avoids the need of intra tumorous puncture. So it appeared as more suitable ablative technique for inconspicuous target with ultrasound or medium size HCC on condition to use proper advanced guidance imaging. Thus because main causes of infeasibility of RFA are nowadays resolved, it is of major interest to value if supra-selective TACE can compete with RFA as first line treatment in curative intent for $\mathrm{HCC} \leq 5 \mathrm{~cm}$. The aim of this study was to compare the treatment failure (defined as local tumor progression and failing to obtain complete response) and the following overall survival in Child-Pugh A cirrhotic patients after RFA versus supra-selective TACE as first line treatment for $\mathrm{HCC} \leq 5 \mathrm{~cm}$ criteria using coarsened exact matching.

\section{RESULTS}

Among the 234 patients with $\mathrm{HCC} \leq 5 \mathrm{~cm}$ (Figure 1), 122 Child A cirrhotic patients treated either by RFA ( $n=$ $61)$ or TACE $(n=61)$ were matched.

\section{Baseline characteristics of RFA and TACE group}

The mean tumor size was $30.2( \pm 10) \mathrm{mm}$ in RFA group and $31( \pm 10) \mathrm{mm}$ in TACE group $(p=0.399) .41 \%$ of patients in each treatment groups had HCC $>30 \mathrm{~mm}$. No significant difference between both groups was seen for baseline characteristics and patients were perfectly matched according to tumor size and serum AFP strata (Table 1). TACE was chosen as first-line treatment due to: inconspicuous nodule on US for 33 patients (54\%); subcapsular location for 10 patients $(16.4 \%)$ and "at risk

\section{4 patients treated for HCC from january 2004 to december 2013}

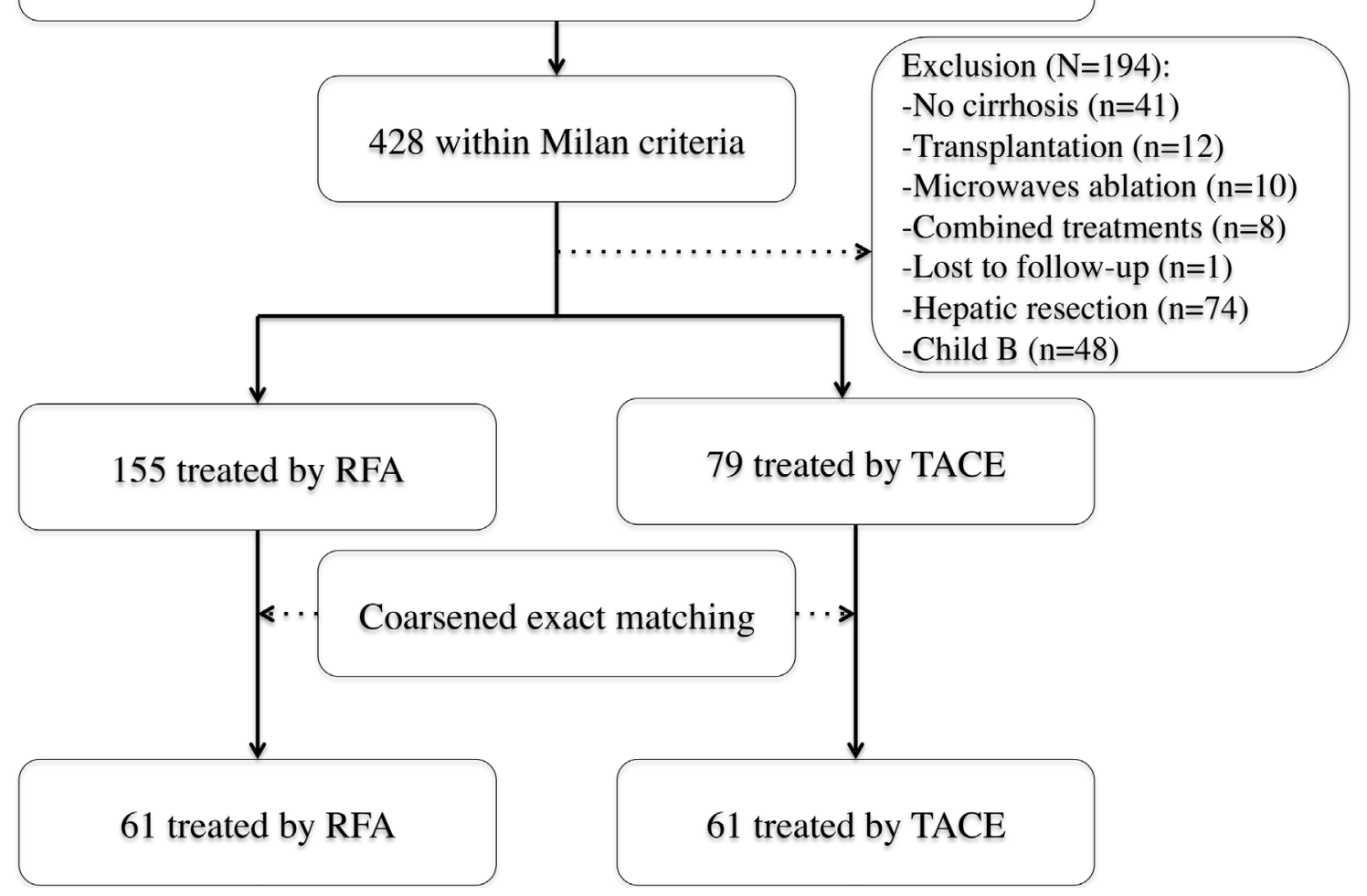

Figure 1: Flow-chart 
Table 1: Demographics and clinical characteristics of Child-Pugh A patients who received radiofrequency ablation (RFA) and transaterial chemoembolization (TACE) for hepatocellular carcinoma $(N=122)$.

\begin{tabular}{|c|c|c|c|}
\hline & RFA group $(n=61)$ & TACE group $(n=61)$ & $P$ value \\
\hline Age $^{* *}$ & $67(11)$ & $67(11)$ & 0.919 \\
\hline Male $n(\%)$ & $50(82)$ & $47(77)$ & 0.501 \\
\hline BMI** & $27.8(4.7)$ & $27.6(5)$ & 0.892 \\
\hline Platelet count $(\mathrm{G} / \mathrm{L})^{*}$ & $122(86-162)$ & $121(81-160)$ & 0.706 \\
\hline \begin{tabular}{ll}
\multicolumn{2}{l}{ Etiologies: } \\
$\bullet \quad$ HCV \\
$\cdot \quad$ Non-viral \\
$\cdot \quad$ Mixed \\
\end{tabular} & $\begin{array}{l}13(21) \\
42(69) \\
6(10)\end{array}$ & $\begin{array}{l}14(23) \\
40(66) \\
7(11)\end{array}$ & 0.922 \\
\hline $\operatorname{AFP}(\mathrm{ng} / \mathrm{ml}) *$ & $10(5-42)$ & $10(4-43)$ & 0.350 \\
\hline $\begin{array}{l}\text { AFP (categorical) } n(\%) \\
-<10 \mathrm{ng} / \mathrm{ml} \\
-10-100 \mathrm{ng} / \mathrm{ml} \\
->100 \mathrm{ng} / \mathrm{ml}\end{array}$ & $\begin{array}{l}30(49) \\
19(31) \\
12(20)\end{array}$ & \begin{tabular}{|l}
$30(49)$ \\
$19(31)$ \\
$12(20)$
\end{tabular} & 1 \\
\hline Tumor size $(\mathrm{cm}) * *$ & $30.2(10)$ & $31(10)$ & 0.399 \\
\hline $\begin{array}{l}\text { Tumor size (categorical) } \mathrm{n}(\%) \\
-<2 \mathrm{~cm} \\
-2-3 \mathrm{~cm} \\
-3.1-5 \mathrm{~cm}\end{array}$ & $\begin{array}{l}8(13) \\
28(46) \\
25(41)\end{array}$ & \begin{tabular}{|l}
$8(13)$ \\
$28(46)$ \\
$25(41)$
\end{tabular} & 1 \\
\hline Multiple nodules: $n(\%)$ & $14(23)$ & $19(31)$ & 0.308 \\
\hline
\end{tabular}

* median (1 and 3 quartiles) and compared with Wilcoxon rank-sum test

** Mean (Standard Deviation) and compared with two sided T-test

Categorical variables are: $\mathrm{n}(\%)$.

Abbreviations: $\mathrm{BMI}=$ Body Mass Index; $\mathrm{HCV}=$ Hepatitis $\mathrm{C}$ virus; $\mathrm{AFP}=$ Alpha-Foeto-protein;

location" for 18 patients $(29.5 \%)$ [13 near hepatic hilum; 2 near colon; 1 near stomach; 1 near the inferior vena cava and one near a sus-hepatic venous].

In RFA group, Monopolar device was used for 19 patients (31\%) and multipolar devices for 42 patients (69\%) (including the 25 patients with $\mathrm{HCC}>3 \mathrm{~cm}$ ).

The mean follow-up was 2.7 years $( \pm 1.9)$; the median follow-up was 2.25 years.

Survival status at the end of the study was available for $121 / 122$ patients. One patient was lost to followup in RFA group after 5.58 years. The rate of liver transplantation did not differ between the two groups, $13 \%$ $(8 / 61)$ in RFA group and $11 \%$ (7/61) in TACE group, $p=$ 0.783 . The mean and median time to transplantation were 2.01 years (range: $0.42-5.44)$ and 2.03 years (1-3 quartiles: $0.98-2.8$ ), respectively.

Median hospitalization duration was 2 days (range: 2-6) in RFA group and 2 days (range 2-7) in TACE group, $p=0.902$.

\section{Treatments failure and predictive factor}

A complete response (CR) was achieved in $100 \%$ of patients in RFA group, with 4 patients $(6.5 \%)$ requiring two ablative sessions. A CR was observed for 47 patients (77\%) in TACE group, after one session for 28 patients (59.5\%), two sessions for 19 patients (40.5\%). The rates of $\mathrm{CR}$ and the number of treatment session to achieve it were significantly different between both groups, $p<0.001$ for both. Eight patients (13.1\%) treated by TACE experienced partial response, two $(3.2 \%)$ stable diseases and four $(6.5 \%)$ progressive diseases as best treatment response.

Local tumor progression was observed in $9.8 \%$ of patients after RFA (6/61) versus $25 \%$ of patients after TACE $(12 / 47), p=0.03$.

Consequently, the rate of treatment failure (primary treatment failure and LTP) was significantly higher after TACE $(42.6 \%)$ than after RFA $(9.8 \%), p<0.001$ (Figure 2).

According to tumor size, $<2 \mathrm{~cm} ; 2-3 \mathrm{~cm}$ and 3.1 $5 \mathrm{~cm}$, treatment failure rates for RFA and TACE were respectively, $12.5 \%(1 / 8), 10.7 \%(3 / 28)$ and $8 \%(2 / 25)$ versus $50 \%(4 / 8), 32 \%(9 / 28)$ and $52 \%(13 / 25)$.

In uni and multivariate analysis (Table 2), supra selective TACE was the only predictive factor of treatment failure, with hazard ratio (95\% CI): 5.573 (2.281 -13.62), $P<0.001$.

Pathological examination of initially treated tumors performed on explanted livers showed a mean necrosis percentage of $96 \%$ (range: $80-100$ ) after RFA versus $61.4 \%$ (range: $20-100)$ after TACE $(p=0.008)$. In RFA group with explanted liver examination $(n=8)$, six patients showed complete tumor necrosis, 1 tumor necrosis equal to $90 \%$ and one $80 \%$. In TACE group with explanted liver pathological examination $(n=7)$, only one patient showed complete tumor necrosis, one equal to $80 \%$, two $70 \%$, one $50 \%$, one $40 \%$ and one $20 \%$. 
Table 2: Predictive factor of treatment failure (primary treatment failure and local tumor progression).

\begin{tabular}{|l|l|l|l|l|}
\hline \multicolumn{1}{|c|}{ Variable } & \multicolumn{1}{|c|}{ Univariate analysis } & \multicolumn{2}{c|}{ Multivariate analysis } \\
\hline Age (years) & $\boldsymbol{P}$ & \multicolumn{1}{c|}{ Hazard ratio (95\%CI) } & $\boldsymbol{P}$ & Hazard ratio (95\%CI) \\
\hline Sex (Male) (\%) & 0.503 & $0.988(0.955-1.022)$ & & \\
\hline BMI & 0.151 & $0.578(0.273-1.218)$ & & \\
\hline Platelet count (<100G/L) & 0.391 & $0.968(0.899-1.042)$ & & \\
\hline Non-Viral hepatitis & 0.517 & $1.268(0.618-2.602)$ & & \\
\hline AFP>100 ng/ml & 0.227 & $1.357(0.827-2.228)$ & & \\
\hline HCC>3cm & 0.250 & $1.605(0.716-3.598)$ & & \\
\hline Multiple nodules & 0.306 & $1.453(0.710-2.974)$ & & \\
\hline TACE (vs RFA) & 0.542 & $1.272(0.586-2.760)$ & & \\
\hline
\end{tabular}

Abbreviations: $\mathrm{BMI}=$ Body Mass Index; ALT=Alanine Amino Transferase; $\mathrm{AFP}=$ Alpha-Foeto-protein; $\mathrm{HCC}=\mathrm{HepatoCellular}$ Carcinoma; $\mathrm{RFA}=$ Radiofrequency ablation; $\mathrm{TACE}=$ transarterial chemoembolization.

\section{Overall survival}

4-years overall survival for RFA and TACE groups were respectively $54.1 \%$ - versus $31.5 \%$, with a mean and median overall survival of 4.6 years ( $95 \%$ CI: $3.6-5.5)$ and 4.9 years (95\% CI: 3.6-6.3) in RFA group versus 3.7 years (95\% CI: $12.8-4.5)$ and 2.4 years (1.7-3.1) in TACE group, $p=0.042$ (Figure 3A).

The factors used to predict overall survival are summarized in Table 3. In univariate analysis, primary treatment failure $(p<0.001)$, TACE $(p=0.045)$, multiple nodules $(p=0.019)$ and serum AFP $>100 \mathrm{ng} / \mathrm{ml}(p=$
0.049 ) were significantly associated with overall survival. In multivariate analysis with the Cox proportional hazards model, primary treatment failure (Hazard Ratio [95\% CI]: 4.163 [2.088-8.298]; $p<0.001)$ and multiple nodules (2.257 [1.261-4.039]; $p=0.006)$ were found to be independent predictive factor associated with overall survival.

\section{Treatments complications}

Two major adverse events occurred after TACE: One treatment-related death in a 79 year-old cirrhotic

\section{Treatment failure}

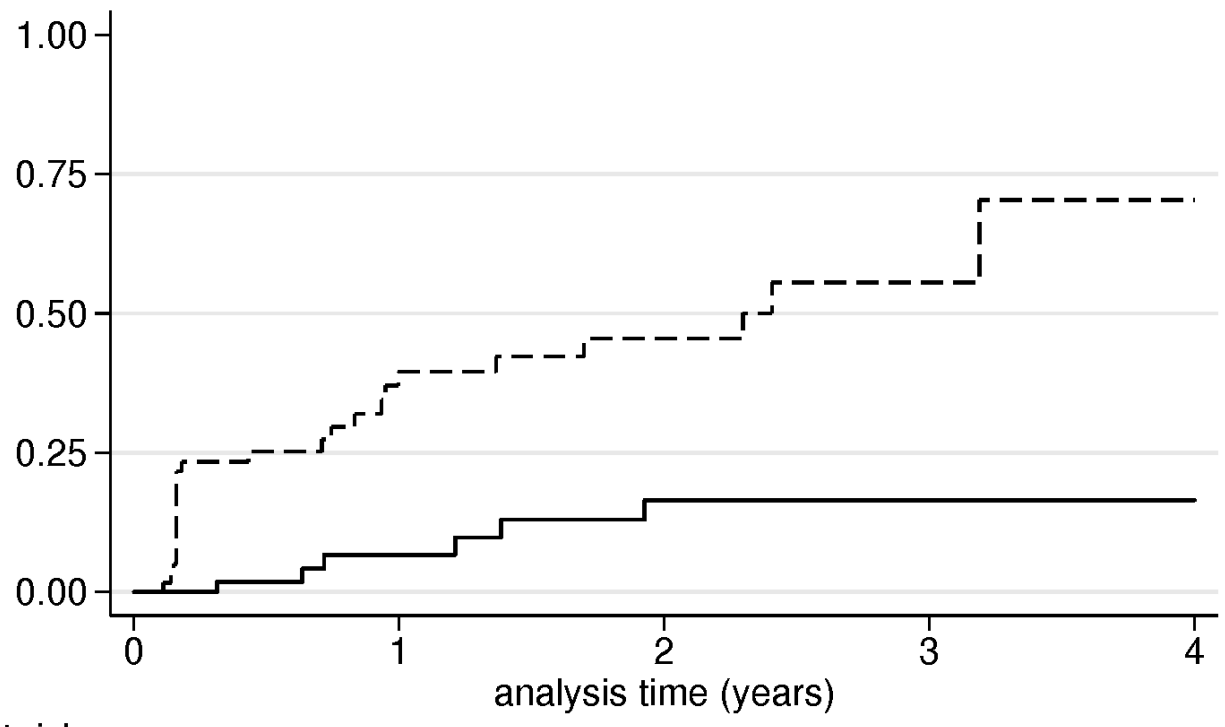

\section{Number at risk}

RFA 61

34

24

TACE 61

24

15

11

8

4

1

RFA ----- TACE

Figure 2: Cumulative incidence of treatment failure after radiofrequency ablation and transarterial chemoembolization. 
patient with Alzheimer disease. He died twenty-eight days after TACE due to lung infection without liver failure. The other major complication was a liver failure requiring a prolonged hospitalization $>48$ hours. In RFA group the major adverse event was abscess developed on ablation site, in the Couinaud segment 2 . The rates of adverse event did not differ between the two groups ( $p=1$, by Fisher exact test).

\section{Progression-free survival (local or intra-hepatic distant recurrence)}

The 4-years progression-free survival for RFA and TACE groups were respectively $29.7 \%$ versus $3 \%$ (Figure 3B) with a mean and median progression-free survival of 2.5 years $(95 \% \mathrm{CI}: 1.8,3.1)$ and 1.4 years $(95 \% \mathrm{CI}: 0.601$, $2.7)$ in RFA group versus 1.4 years (95\% CI: $1.1-1.7)$ and 0.95 years $(0.6-1.3)$ in TACE group, $p=0.009$.

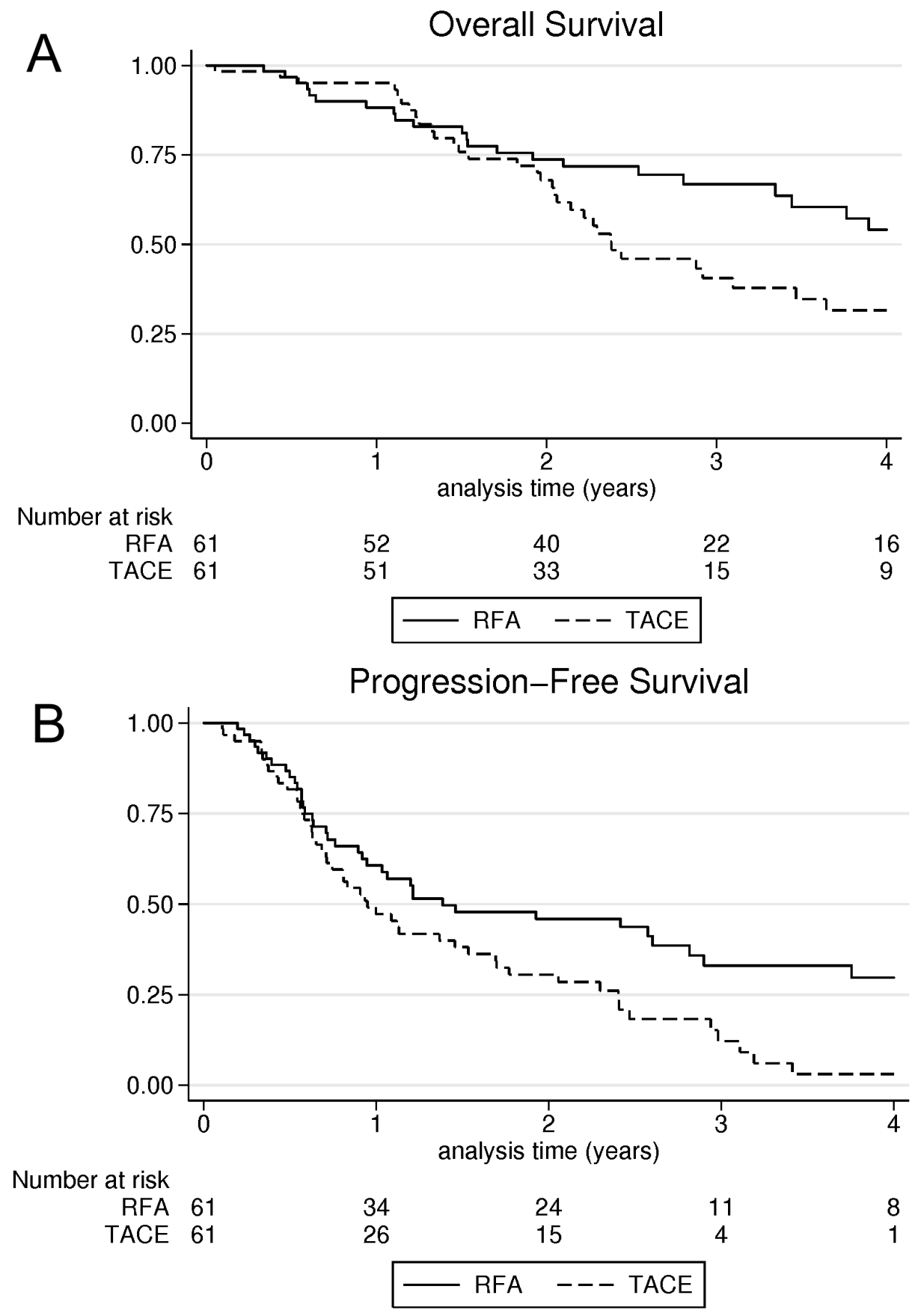

Figure 3: A. overall survival comparison between radiofrequency ablation and trans-arterial chemoembolization; B. Progressionfree survival comparison between radiofrequency ablation and trans-arterial chemoembolization. 
Table 3: Univariate and multivariate cox analysis for factors associated with overall survival for hepatocellular carcinoma patients treated by radiofrequency ablation (RFA) or transarterial chemoembolization (TACE) $(n=122)$

\begin{tabular}{|c|c|c|c|c|}
\hline \multirow[t]{2}{*}{ Variable } & \multicolumn{2}{|r|}{ Univariate analysis } & \multicolumn{2}{|r|}{ Multivariate analysis } \\
\hline & $P$ & Hazard ratio $(95 \% \mathrm{CI})$ & $P$ & Hazard ratio $(95 \% \mathrm{CI})$ \\
\hline Age (years) & 0.922 & $0.998(0.973-1.024)$ & & \\
\hline Sex (Male) (\%) & 0.727 & $0.891(0.468-1.696)$ & & \\
\hline BMI & 0.097 & $0.952(0.899-1.008)$ & & \\
\hline Platelet count $(<100 \mathrm{G} / \mathrm{L})$ & 0.119 & $1.537(0.895-2.640)$ & & \\
\hline Non-Viral hepatitis & 0.527 & $1.122(0.656-2.274)$ & & \\
\hline $\mathrm{AFP}>100 \mathrm{ng} / \mathrm{ml}$ & 0.049 & $1.799(1.00-3.230)$ & & \\
\hline $\mathrm{HCC}>3 \mathrm{~cm}$ & 0.641 & $1.138(0.660-1.963)$ & & \\
\hline Multiple nodules & 0.019 & $1.987(1.122-3.519)$ & 0.006 & 2.257 (1.261-4.039) \\
\hline Primary treatment failure & $<0.001$ & 3.641 (1.853-7.154) & $<0.001$ & $4.163(2.088-8.298)$ \\
\hline TACE (vS RFA) & 0.045 & $1.746(1.012-3.012)$ & & \\
\hline
\end{tabular}

Abbreviations: $\mathrm{BMI}=$ Body Mass Index; $\mathrm{ALT}=$ Alanine Amino Transferase; $\mathrm{AFP}=$ Alpha-Foeto-protein; $\mathrm{HCC}=\mathrm{HepatoCellular}$ Carcinoma; $\mathrm{RFA}=$ Radiofrequency ablation; $\mathrm{TACE}=$ transarterial chemoembolization.

Factors associated with progression-free survival are summarized in Table 4. In univariate analysis, primary treatment failure $(p<0.001)$ and TACE $(p=0.011)$ were significantly associated with progression-free survival. In multivariate analysis with the Cox proportional hazards model, primary treatment failure was the only predictive factor associated with progression-free survival, Hazard Ratio: 3.976 (95\% CI: 2.175-7.267), $p<0.001$. Nineteen patients (31\%) in RFA group and 27 patients (44\%) in TACE group experienced recurrence beyond Milan criteria: 5 secondary to tumor size ( 3 after RFA and 2 after TACE); 22 secondary to intra-liver multifocal recurrences ( 7 in RFA and 15 in TACE); 8 secondary to infiltrative HCC (6 in RFA group and 2 in TACE group); 7 secondary to intra-vascular tumoral extension ( 1 after RFA and 6 after TACE); 3 secondary to lung $(n=1)$, adrenal gland ( $n$ $=1$ ) or lymph node $(n=1)$ metastasis (one after RFA and 2 after TACE) and one due to intra-ductal recurrence (1 after RFA and none after TACE).

\section{DISCUSSION}

In this study, we investigated the local tumor control and survival benefits of RFA and TACE with a coarsened exact matching method. It provided a perfect matching for tumor size and serum AFP strata. When RFA cannot be performed under US guidance due to inconspicuous nodule, TACE appears like an attractive treatment alternative especially for $\mathrm{HCC} \leq 5 \mathrm{~cm}$, if cone-beam $\mathrm{CT}$, CT-Scan or imaging fusion guidance are not available. However the rate of primary treatment failure (failing to achieve complete response) following TACE reached $23 \%$ in our cohort and $25 \%$ in Kim et al study [14] that is significantly higher than RFA (no primary treatment failure), $p<0.001$. Beyond primary treatment failure, RFA can produce supra centimeter safety margin that limit the local recurrence rate $[20,21]$. At odds supra-selective
cTACE does not seems able to produce safety margin [22] due to the lack of portal vein embolization [23] that lead to a high local recurrence rate ( $25 \%$ in our study) despite primary treatment success. So treatment failure rates reached $42.6 \%$ after TACE versus $9.8 \%$ after RFA $(p<0.001)$. LTP and primary treatment failure are both predictive factor of poor outcome [24] as illustrated by the multivariate cox model selecting primary treatment failure as the main prognostic factor of OS (HR: 4.163) and PFS (HR: 3.976). Despite a high mean tumor size $(3 \mathrm{~cm}$ in each group) with $41 \%$ of patients with tumor $>3 \mathrm{~cm}$, we did not observed an increase of treatment failure using RFA for $\mathrm{HCC}>3 \mathrm{~cm}$ (around 10\%) while Kim et al [15] and Cartier et al [19] reported a LTP rate $>70 \%$ for medium size HCC using Monopolar RFA. This excellent local tumor control for $3.1-5 \mathrm{~cm}$ HCC is explained by using multipolar devices that offer a larger and more homogeneous necrotic area [16, 17, 25-27] than monopolar devices even using overlapping technic [28]. Several authors [15, 29] tested the combination of monopolar RFA with TACE for HCC $<$ or $=5 \mathrm{~cm}$. Compared with RFA alone, improvement of LTP have been reported only for tumor $>$ or $=3 \mathrm{~cm}$ in diameter. This strategy could be also interesting for tumor inconspicuous at unenhanced imaging (US or CT).

The 4-years overall survival after RFA and TACE were similar to previous publication studying western cirrhotic patients $[30,31]$ but at odds to previous eastern studies [12, 14], RFA offered a better OS than supraselective TACE for HCC $\leq 5 \mathrm{~cm}(\mathrm{P}=0.042)$. The better OS and PFS provided by RFA compared to TACE could be explained par the lower rate of treatment failure but also by the higher rate of complete pathological tumor necrosis provided by RFA. Indeed on the explanted liver pathological examination we found that $6 / 8$ (75\%) tumor treated by RFA were completely necrosis while only $1 / 7(14.2 \%)$ tumor treated by TACE showed complete necrosis. Allard et al [32] emphasized a clear benefice 
Table 4: Univariate and multivariate cox analysis for predictive factor of HCC recurrence.

\begin{tabular}{|l|l|l|l|l|}
\hline \multicolumn{1}{|c|}{ Variable } & \multicolumn{1}{|c|}{ Univariate analysis } & \multicolumn{2}{c|}{ Multivariate analysis } \\
\hline & \multicolumn{1}{|c|}{$\boldsymbol{P}$} & \multicolumn{1}{c|}{ Hazard ratio (95\%CI) } & $\boldsymbol{P}$ & Hazard ratio (95\%CI) \\
\hline Age (years) & 0.110 & $0.983(0.63-1.003)$ & & \\
\hline Sex (Male) (\%) & 0.944 & $0.981(0.583-1.650)$ & & \\
\hline BMI & 0.720 & $0.992(0.950-1.036)$ & & \\
\hline Platelet count (<100G/L) & 0.232 & $1.304(0.843-2.016)$ & & \\
\hline Non-Viral hepatitis & 0.227 & $1.357(0.827-2.228)$ & & \\
\hline AFP $>\mathbf{1 0 0}$ ng/ml & $\mathbf{0 . 1 0 0}$ & $\mathbf{1 . 5 2 1}(\mathbf{0 . 9 1 1 - 2 . 5 3 9 )}$ & & \\
\hline HCC $>\mathbf{3 c m}$ & 0.707 & $1.008(0.709-1.657)$ & & \\
\hline Multiple nodules & 0.171 & $1.385(0.869-2.209)$ & & \\
\hline Primary treatment failure & $<\mathbf{0 . 0 0 1}$ & $\mathbf{3 . 9 7 6}(\mathbf{2 . 1 7 5 - 7 . 2 6 7 )}$ & $<\mathbf{0 . 0 0 1}$ & $\mathbf{3 . 9 7 6}(\mathbf{2 . 1 7 5 - 7 . 2 6 7 )}$ \\
\hline TACE (vs RFA) & $\mathbf{0 . 0 1 1}$ & $\mathbf{1 . 7 5 3 ( 1 . 1 3 8 - 2 . 7 0 1 )}$ & & \\
\hline
\end{tabular}

Abbreviations: $\mathrm{BMI}=$ Body Mass Index; $\mathrm{ALT}=$ Alanine Amino Transferase; $\mathrm{AFP}=$ Alpha-Foeto-protein; $\mathrm{HCC}=\mathrm{HepatoCellular}$ Carcinoma; RFA= Radiofrequency ablation; $\mathrm{TACE}=$ transarterial chemoembolization

of a pathological tumor necrosis higher than $90 \%$ after TACE on survival after liver transplantation or liver resection. On the same line, Seror et al [17] published that pathological complete necrosis is achieved in more than $90 \%$ of cases using no touch multibipolar RFA while the rate of pathological complete necrosis is around $60 \%$ after TACE [33]. Moreover, recently drug-eluted beads TACE (DEB-TACE) appears as the main alternative to Lipiodol-TACE with a better pharmacological profile but without translation in better tumor response or survival in multicentric propective trials [34, 35].

Considering the better local tumor control leading to better OS and PFS offered by RFA compared to TACE, RFA should be the standard treatment used as firstline. In case of inconspicuous nodule, TACE should be considered, only when the tumor still unnameable to RFA using advanced technologies for ablation like multibipolar RFA and or for imaging guidance like CT, US fused with CT or MRI or Cone-Beam CT or guidance Indeed ConeBeam CT since using these techniques 100\% primary treatment success has been reported in preliminary reports $[6,7]$.

Nevertheless, our study has several limitations. The main limitation is the retrospective design although we used coarsened exact matching to avoid selection bias and none patient was lost to follow-up at 5 years. In our study, HCC treated by TACE were mostly inconspicuous on US and or in challenging location for electrode placement. Although this characteristic in our knowledge has never been associated with more aggressive natural tumor grow pattern, it is possible that in that circumstance the trickier radiofrequency needle placement even assisted with advanced imaging-guidance, leads to a higher rate of local tumor progression compared to easier radiofrequency treatment.

No systematic pre-treatment tumor biopsies are performed so tumor differentiations are not known, and cannot be included in matching model.
Despite a high complete response rate (77\%), supraselective TACE is associated with a higher treatment failure (local tumor progression and primary treatment failure) and lower overall survival than RFA using mainly multipolar device. In case of inconspicuous nodule $\leq 5 \mathrm{~cm}$, all efforts have to be made using proper technologies (ablation and guidance) to perform RFA rather than TACE.

\section{PATIENTS AND METHODS}

The study protocol conforms to the ethical guidelines of the 1975 Declaration of Helsinki and was approved by the institution's human research committee. Informed consent was not necessary for this retrospective analysis of our data.

\section{Patients}

Patients' data were collected from a prospectively maintained and computerized database recording: age, sex, cirrhosis etiology, Child score, Platelet count, serum $\alpha$-fetoprotein level (AFP), number and size of $\mathrm{HCC}$, treatment, results of pathological radiological and pathological examinations. We included all consecutive cirrhotic, Ecog-0 and child-Pugh A patients with single $\mathrm{HCC} \leq 5 \mathrm{~cm}$ or $\leq$ three nodules $\leq 3 \mathrm{~cm}$ unsuitable for surgery, without extrahepatic metastasis (early-stage HCC), treated by first line RFA or supraselective TACE from January 2004 to December 2013 according the decision of local tumor boards. Additional criteria were: (i) Child-Pugh A; (ii) no other cancer. Exclusion criteria were: (i) Child-Pugh B; (ii) lost-to-follow-up before the first imaging control; (iii) combined treatment (RFA plus TACE or RFA plus surgery); (iv) treated by microwaves ablation; (v) ill-defined tumor. Then patients were matched in two groups according to treatment type: (i) RFA; (ii) TACE according to demographic data, surrogate marker of cirrhosis severity, serum AFP and tumor characteristics. 


\section{Diagnosis of HCC}

All patients were cirrhotic. Cirrhosis was histologically proven for 55 patients $(45 \%)$, and based on liver stiffness, imaging and blood sample analysis for the 67 remaining patients $(55 \%)$. Non-invasive criteria of the European Association for the Study of the Liver (EASL) were used to diagnose HCC in cirrhotic patients [1]. Diagnosis was performed on multiphase liver MRI or CT-Scan. Nodule was diagnosed as HCC if it was hypervascular in the arterial phase with washout in the portal venous or delayed phases $(n=83,68 \%)$. Tumor biopsies with pathologic confirmation were performed for patients who did not meet the non-invasive diagnostic criteria $(n=39,32 \%)$.

\section{Radiofrequency ablation}

All RFA procedures were performed percutaneously under general anaesthesia. Real-time ultrasound (US) with a 4-MHz probe was chosen as guidance modality for all patients. Five senior interventional radiologists (at least five years of experience) performed RFA using one of the following devices: monopolar expandable Boston LeVeen ${ }^{\mathrm{TM}}$ needles (RF 3000 Boston Scientific Corporate ${ }^{\circledR}$ ), or multipolar internally cooled-tip CelonProSurge ${ }^{\mathrm{TM}}$ (CelonPOWER System OLYMPUS Medical ${ }^{\circledR}$ ) (available in our center since 2006) [18]. The device was chosen based on the operator's expertise, the tumour shape, size, location and vascular proximity. Operators used multipolar device for $\geq 3 \mathrm{~cm}$ and in case of vascular proximity. The thermal ablation was performed according to the manufacturer's instructions. Real-time procedure control of RFA was performed with ultrasound examination.

\section{TACE procedure}

The same interventional radiologist performing RFA have performed supraselective TACE (at least five years experience). Portal vein permeability was checked by ultrasound examination before TACE. The transfemoral approach was carried out under local anaesthesia using 4-Fr angiographic catheters. The coeliac and hepatic arteries were catheterized with Cobra or Simmons 4-Fr (Terumo); next segmental and subsegmental tumor feeding arteries was catheterized using micro-catheter PROGREAT (Terumo) 2.8-Fr. An emulsion of $10 \mathrm{ml}$ iodized oil (Lipiodol; Andre Guerbet, France) and doxorubicin hydrochloride (50 $\mathrm{mg}$ in $10 \mathrm{ml}$ ) was infused through the feeder vessels. Then embolization was performed using a mixture of gelatin sponge particles and contrast material until reaching a stasis flux.

\section{Treatment choice}

Treatments were decided upon in a multidisciplinary team meeting and the treatment option was chosen based on guidelines [1]. For early-stage HCC unsuitable for surgery, RFA was the first-line treatment. Before that protective manoeuvre as hydrodiscection and/or advanced guidance technologies as fusion US-CT or MR became routinely used or available in our center we preferably chose TACE for inconspicuous nodule on US or nodule with "at risk location" (near gallbladder, bile duct or gastro-intestinal tract). In case of local tumor progression, if HCC was seen on US examination RFA was the first treatment choice, if not TACE was performed.

\section{Patient follow up}

Oncologic follow-up was performed with MRI (or CT-scan in case of contra-indication of MRI) at one month and then each three months for the liver and by chest CT-scan every six months. For TACE, the onemonth follow-up consisted in an association of liver MRI and Thoracoabdominal unhanced-CT-scan to evaluate the tumor iodized oil labeling.

\section{Study endpoint}

\section{Treatment failure}

The main endpoint of the study was to compare treatment failure rates defined as primary treatment failure or local tumor progression during follow-up [19]. Primary treatment failure was defined as failing to achieve complete treatment response according to mRECIST after up to two TACE or RFA. Local tumor progression (LTP) described by the appearance of tumor foci at the edge of the ablation zone, after at least one contrast-enhanced follow-up study has documented adequate ablation and an absence of viable tissue in the target tumor by using imaging criteria. This term applies regardless of when tumor foci were discovered either early or late in the course of imaging follow-up [36].

\section{Survival}

Secondary endpoints were to compare: (i) overall survival defined as time to last follow-up evaluation or death (patients with liver transplantation were censored at the date of transplantation) measured from the date of treatment; (ii) Progression-Free survival defines as the time interval between initial treatment and radiological progression (local or intra-hepatic distant recurrence).

\section{Complications}

Post-treatment morbi-mortality was collected and perioperative mortality was defined as death 
within 30 days of treatment. Morbidity was stratified as recommended by the Society of Interventional Radiology [37].

\section{Statistical analysis}

To control selection bias and provide a more accurate matching on prognosis factor than using only propensity score we used one-to-one coarsened exact matching (CEM). Briefly, The idea of CEM is coarsen each variable into substantively meaningful groups on then to perform exact match on these coarsened data [38]. CEM was performed using three variables: Tumor size (categorized as $<20 \mathrm{~mm} ; 20-30 \mathrm{~mm}$ and $>30 \mathrm{~mm}$ ); Serum AFP (categorized as $<10 \mathrm{ng} / \mathrm{ml} ; 10-100 \mathrm{ng} / \mathrm{ml}$ and $>100 \mathrm{ng} / \mathrm{ml}$ ); and a propensity score variable including: age, sex, BMI, tumor number, platelet count and cirrhosis etiology .The propensity score variable was categorized with a caliper of 0.2. Tumor size and serum AFP were included separately in CEM to achieve exact matching on them because they are the main prognostic factors of survival and recurrence $[24,27,30]$.

Data are expressed as mean ( \pm standard deviation) or median ( $1^{\text {st }}-3^{\text {rd }}$ quartiles) and compared using either the two-sample $t$-test or the Mann-Whitney test, according to data distribution. Percentages were compared using the Chi-2 test or Fisher's exact test. Survival without treatment failure and overall survival were computed by the Kaplan-Meier method and compared by the logrank test. To identify factors associated with treatment failure; we first performed univariate analysis using univariate Cox regression. Variables with $p<0.1$ were then introduced in a multivariate Cox Model and hazard ratios (HR) and corresponding 95\% confidence intervals (CI) reported. Patients with primary treatment failure were censored at the date of the second treatment session. Twosided statistical tests were used for all analyses. A $p$-value $<0.05$ was considered as significant. Statistical analyses were performed with Stata 13.

\section{Abbreviations and acronyms}

$\mathrm{HCC}=$ Hepatocellular carcinoma

$\mathrm{SR}=$ surgery resection

RFA $=$ radiofrequency ablation

TACE $=$ transarterial chemoembolization

$\mathrm{CR}=$ complete response

LTP $=$ local tumor progression

$\mathrm{CEM}=$ Coarsened exact matching

\section{CONFLICT OF INTEREST}

The authors declare no conflicts of interest.

\section{FINANCIAL SUPPORT}

No financial support was received for this study.

\section{REFERENCES}

1. European Association For The Study Of The Liver, European Organisation For Research And Treatment Of Cancer. EASL-EORTC clinical practice guidelines: management of hepatocellular carcinoma. J Hepatol. 2012; 56: 908-43. doi: 10.1016/j.jhep.2011.12.001.

2. Kim JE, Kim YS, Rhim H, Lim HK, Lee MW, Choi D, Shin SW, Cho SK. Outcomes of patients with hepatocellular carcinoma referred for percutaneous radiofrequency ablation at a tertiary center: analysis focused on the feasibility with the use of ultrasonography guidance. Eur J Radiol. 2011; 79: e80-84. doi: 10.1016/j.ejrad.2011.03.090.

3. Teratani T, Yoshida H, Shiina S, Obi S, Sato S, Tateishi R, Mine N, Kondo Y, Kawabe T, Omata M. Radiofrequency ablation for hepatocellular carcinoma in so-called highrisk locations. Hepatol Baltim Md. 2006; 43: 1101-8. doi: 10.1002/hep.21164.

4. Song KD, Lee MW, Rhim H, Cha DI, Chong Y, Lim HK. Fusion imaging-guided radiofrequency ablation for hepatocellular carcinomas not visible on conventional ultrasound. AJR Am J Roentgenol. 2013; 201: 1141-7. doi: 10.2214/AJR.13.10532.

5. Min JH, Lim HK, Lim S, Kang TW, Song KD, Choi SY, Rhim H, Lee MW. Radiofrequency ablation of very-earlystage hepatocellular carcinoma inconspicuous on fusion imaging with B-mode US: value of fusion imaging with contrast-enhanced US. Clin Mol Hepatol. 2014; 20: 61-70. doi: 10.3350/cmh.2014.20.1.61.

6. Cazzato RL, Buy X, Alberti N, Fonck M, Grasso RF, Palussière J. Flat-panel cone-beam CT-guided radiofrequency ablation of very small $(\leq 1.5 \mathrm{~cm})$ liver tumors: technical note on a preliminary experience. Cardiovasc Intervent Radiol. 2015; 38: 206-12. doi: 10.1007/s00270-014-1019-6.

7. Morimoto M, Numata K, Kondo M, Nozaki A, Hamaguchi S, Takebayashi S, Tanaka K. C-arm cone beam CT for hepatic tumor ablation under real-time 3D imaging. AJR Am J Roentgenol. 2010; 194: W452-454. doi: 10.2214/ AJR.09.3514.

8. Koda M, Ueki M, Maeda Y, Mimura K, Okamoto K, Matsunaga Y, Kawakami M, Hosho K, Murawaki Y. Percutaneous sonographically guided radiofrequency ablation with artificial pleural effusion for hepatocellular carcinoma located under the diaphragm. AJR Am J Roentgenol. 2004; 183: 583-8. doi: 10.2214/ ajr.183.3.1830583.

9. Song I, Rhim H, Lim HK, Kim YS, Choi D. Percutaneous radiofrequency ablation of hepatocellular carcinoma abutting the diaphragm and gastrointestinal tracts with the use of artificial ascites: safety and technical efficacy in 
143 patients. Eur Radiol. 2009; 19: 2630-40. doi: 10.1007/ s00330-009-1463-x.

10. Golfieri R, Cappelli A, Cucchetti A, Piscaglia F, Carpenzano M, Peri E, Ravaioli M, D’Errico-Grigioni A, Pinna AD, Bolondi L. Efficacy of selective transarterial chemoembolization in inducing tumor necrosis in small ( $<5 \mathrm{~cm}$ ) hepatocellular carcinomas. Hepatology. 2011; 53: 1580-9. doi: 10.1002/hep.24246.

11. Manini MA, Sangiovanni A, Martinetti L, Viganò D, La Mura V, Aghemo A, Iavarone M, Crespi S, Nicolini A, Colombo M. Transarterial chemoembolization with drugeluting beads is effective for the maintenance of the Milanin status in patients with a small hepatocellular carcinoma. Liver Transplant Off Publ Am Assoc Study Liver Dis Int Liver Transplant Soc. 2015; 21: 1259-69. doi: 10.1002/ 1t.24196.

12. Hsu CY, Huang YH, Chiou YY, Su CW, Lin HC, Lee RC, Chiang JH, Huo TI, Lee FY, Lee SD. Comparison of radiofrequency ablation and transarterial chemoembolization for hepatocellular carcinoma within the Milan criteria: a propensity score analysis. Liver Transplant Off Publ Am Assoc Study Liver Dis Int Liver Transplant Soc. 2011; 17: 556-66. doi: 10.1002/1t.22273.

13. Yang HJ, Lee JH, Lee DH, Yu SJ, Kim YJ, Yoon JH, Kim HC, Lee JM, Chung JW, Yi NJ, Lee KW, Suh KS, Lee HS. Small single-nodule hepatocellular carcinoma: comparison of transarterial chemoembolization, radiofrequency ablation, and hepatic resection by using inverse probability weighting. Radiology. 2014; 271: 909-18. doi: 10.1148/ radiol.13131760.

14. Kim JW, Kim JH, Sung KB, Ko HK, Shin JH, Kim PN, Choi HK, Ko GY, Yoon HK, Chun SY, Gwon DI. Transarterial chemoembolization vs. radiofrequency ablation for the treatment of single hepatocellular carcinoma $2 \mathrm{~cm}$ or smaller. Am J Gastroenterol. 2014; 109: 1234-40. doi: 10.1038/ajg.2014.152.

15. Kim JH, Won HJ, Shin YM, Kim SH, Yoon HK, Sung KB, Kim PN. Medium-sized (3.1-5.0 cm) hepatocellular carcinoma: transarterial chemoembolization plus radiofrequency ablation versus radiofrequency ablation alone. Ann Surg Oncol. 2011; 18: 1624-9. doi: 10.1245/ s10434-011-1673-8.

16. Hocquelet A, Aubé C, Rode A, Cartier V, Sutter O, Manichon AF, Boursier J, N'kontchou G, Merle P, Blanc JF, Trillaud H, Seror O. Comparison of NoTouch MultiBipolar vs. Monopolar radiofrequency ablation for small HCC. J Hepatol. 2016; . doi: 10.1016/j.jhep.2016.07.010.

17. Seror O, N'Kontchou G, Van Nhieu JT, Rabahi Y, Nahon P, Laurent A, Trinchet JC, Cherqui D, Vicaut E, Beaugrand M, Sellier N. Histopathologic comparison of monopolar versus no-touch multipolar radiofrequency ablation to treat hepatocellular carcinoma within Milan criteria. J Vasc Interv Radiol JVIR. 2014; 25: 599-607. doi: 10.1016/j. jvir.2013.11.025.

18. Seror O, N'Kontchou G, Nault JC, Rabahi Y, Nahon
P, Ganne-Carrié N, Grando V, Zentar N, Beaugrand M, Trinchet JC, Diallo A, Sellier N. Hepatocellular Carcinoma within Milan Criteria: No-Touch Multibipolar Radiofrequency Ablation for Treatment-Long-term Results. Radiology. 2016; : 150743. doi: 10.1148/ radiol.2016150743.

19. Cartier V, Boursier J, Lebigot J, Oberti F, Fouchard-Hubert I, Aubé C. Radiofrequency ablation of hepatocellular carcinoma: Mono or multipolar? J Gastroenterol Hepatol. 2015; . doi: 10.1111/jgh.13179.

20. Kim KW, Lee JM, Klotz E, Kim SJ, Kim SH, Kim JY, Han JK, Choi BI. Safety margin assessment after radiofrequency ablation of the liver using registration of preprocedure and postprocedure CT images. AJR Am J Roentgenol. 2011; 196: W565-572. doi: 10.2214/AJR.10.5122.

21. Hocquelet A, Trillaud H, Frulio N, Papadopoulos P, Balageas P, Salut C, Meyer M, Blanc JF, Montaudon M, Denis de Senneville B. Three-Dimensional Measurement of Hepatocellular Carcinoma Ablation Zones and Margins for Predicting Local Tumor Progression. J Vasc Interv Radiol JVIR. 2016; . doi: 10.1016/j.jvir.2016.02.031.

22. Miyayama S, Matsui O, Yamashiro M, Ryu Y, Kaito K, Ozaki K, Takeda T, Yoneda N, Notsumata K, Toya D, Tanaka N, Mitsui T. Ultraselective transcatheter arterial chemoembolization with a 2-f tip microcatheter for small hepatocellular carcinomas: relationship between local tumor recurrence and visualization of the portal vein with iodized oil. J Vasc Interv Radiol JVIR. 2007; 18: 365-76. doi: 10.1016/j.jvir.2006.12.004.

23. Idée JM, Guiu B. Use of Lipiodol as a drug-delivery system for transcatheter arterial chemoembolization of hepatocellular carcinoma: a review. Crit Rev Oncol Hematol. 2013; 88: 530-49. doi: 10.1016/j. critrevonc.2013.07.003.

24. Lee DH, Lee JM, Lee JY, Kim SH, Yoon JH, Kim YJ, Han JK, Choi BI. Radiofrequency Ablation of Hepatocellular Carcinoma as First-Line Treatment: Long-term Results and Prognostic Factors in 162 Patients with Cirrhosis. Radiology. 2013; : 130940. doi: 10.1148/radiol.13130940.

25. Seror O, N'Kontchou G, Ibraheem M, Ajavon Y, Barrucand C, Ganne N, Coderc E, Trinchet JC, Beaugrand M, Sellier N. Large ( $>$ or $=5.0-\mathrm{cm}$ ) HCCs: multipolar RF ablation with three internally cooled bipolar electrodes - initial experience in 26 patients. Radiology. 2008; 248: 288-96. doi: 10.1148/radiol.2481071101.

26. Seror O, N'Kontchou G, Nault JC, Rabahi Y, Nahon P, Ganne-Carrié N, Grando V, Zentar N, Beaugrand M, Trinchet JC, Diallo A, Sellier N. Hepatocellular Carcinoma within Milan Criteria: No-Touch Multibipolar Radiofrequency Ablation for Treatment-Long-term Results. Radiology. 2016; 150743. doi: 10.1148/radiol.2016150743.

27. Hocquelet A, Balageas P, Laurent C, Blanc JF, Frulio N, Salut C, Cassinotto C, Saric J, Possenti L, Bernard $\mathrm{PH}$, Montaudon M, Trillaud H. Radiofrequency ablation versus surgical resection for hepatocellular carcinoma 
within the Milan criteria: A study of 281 Western patients. Int J Hyperth Off J Eur Soc Hyperthermic Oncol North Am Hyperth Group. 2015; 1-9. doi: 10.3109/02656736.2015.1068382.

28. Dodd GD, Frank MS, Aribandi M, Chopra S, Chintapalli KN. Radiofrequency thermal ablation: computer analysis of the size of the thermal injury created by overlapping ablations. AJR Am J Roentgenol. 2001; 177: 777-82. doi: 10.2214/ajr.177.4.1770777.

29. Morimoto M, Numata K, Kondou M, Nozaki A, Morita S, Tanaka K. Midterm outcomes in patients with intermediatesized hepatocellular carcinoma: a randomized controlled trial for determining the efficacy of radiofrequency ablation combined with transcatheter arterial chemoembolization. Cancer. 2010; 116: 5452-60. doi: 10.1002/cncr.25314.

30. N'Kontchou G, Mahamoudi A, Aout M, Ganne-Carrié N, Grando V, Coderc E, Vicaut E, Trinchet JC, Sellier N, Beaugrand M, Seror O. Radiofrequency ablation of hepatocellular carcinoma: long-term results and prognostic factors in 235 Western patients with cirrhosis. Hepatol Baltim Md. 2009; 50: 1475-83. doi: 10.1002/hep.23181.

31. Terzi E, Piscaglia F, Forlani L, Mosconi C, Renzulli M, Bolondi L, Golfieri R, BLOG-Bologna Liver Oncology Group, S.Orsola-Malpighi Hospital, University of Bologna, Bologna, Italy. TACE performed in patients with a single nodule of Hepatocellular Carcinoma. BMC Cancer. 2014; 14: 601. doi: 10.1186/1471-2407-14-601.

32. Allard MA, Sebagh M, Ruiz A, Guettier C, Paule B, Vibert E, Cunha AS, Cherqui D, Samuel D, Bismuth H, Castaing D, Adam R. Does Pathological Response for Hepatocellular Carcinoma in Patients with Cirrhosis Predict Outcome after Liver Resection or Transplantation? J Hepatol. 2015; . doi: 10.1016/j.jhep.2015.01.023.

33. Bargellini I, Bozzi E, Campani D, Carrai P, De Simone P, Pollina L, Cioni R, Filipponi F, Bartolozzi C. Modified
RECIST to assess tumor response after transarterial chemoembolization of hepatocellular carcinoma: CTpathologic correlation in 178 liver explants. Eur J Radiol. 2013; 82: e212-218. doi: 10.1016/j.ejrad.2012.12.009.

34. Vesselle G, Quirier-Leleu C, Velasco S, Charier F, Silvain C, Boucebci S, Ingrand P, Tasu JP. Predictive factors for complete response of chemoembolization with drug-eluting beads (DEB-TACE) for hepatocellular carcinoma. Eur Radiol. 2015; . doi: 10.1007/s00330-015-3982-y.

35. Golfieri R, Giampalma E, Renzulli M, Cioni R, Bargellini I, Bartolozzi C, Breatta AD, Gandini G, Nani R, Gasparini D, Cucchetti A, Bolondi L, Trevisani F, et al. Randomised controlled trial of doxorubicin-eluting beads $v s$ conventional chemoembolisation for hepatocellular carcinoma. Br J Cancer. 2014; 111: 255-64. doi: 10.1038/bjc.2014.199.

36. Ahmed M, Solbiati L, Brace CL, Breen DJ, Callstrom MR, Charboneau JW, Chen MH, Choi BI, de Baère T, Dodd GD, Dupuy DE, Gervais DA, Gianfelice D, et al. Imageguided tumor ablation: standardization of terminology and reporting criteria - a 10-year update. Radiology. 2014; 273 : 241-60. doi: 10.1148/radiol.14132958.

37. Cardella JF, Kundu S, Miller DL, Millward SF, Sacks D, Society of Interventional Radiology. Society of Interventional Radiology clinical practice guidelines. J Vasc Interv Radiol JVIR. 2009; 20: S189-191. doi: 10.1016/j. jvir.2009.04.035.

38. Blackwell M, Iacus S, King G, Porro G. CEM: Coarsened Exact Matching in Stata. Stata J. 2009; 9: 524-546. 